\title{
ANN Model-Based Simulation of the Runoff Variation in Response to Climate Change on the Qinghai-Tibet Plateau, China
}

\author{
Chang Juan, ${ }^{1}$ Wang Genxu, ${ }^{2}$ Mao Tianxu, ${ }^{2}$ and Sun Xiangyang ${ }^{2}$ \\ ${ }^{1}$ Key Laboratory of Western China's Environmental Systems, Ministry of Education, College of Earth and Environmental Science, \\ Lanzhou University, Lanzhou 730000, China \\ ${ }^{2}$ Institute of Mountain Hazards and Environment, CAS, Chengdu 610041, China
}

Correspondence should be addressed to Chang Juan; changjuan@lzu.edu.cn

Received 21 February 2017; Revised 21 April 2017; Accepted 4 May 2017; Published 9 July 2017

Academic Editor: Ravinesh C. Deo

Copyright (C) 2017 Chang Juan et al. This is an open access article distributed under the Creative Commons Attribution License, which permits unrestricted use, distribution, and reproduction in any medium, provided the original work is properly cited.

\begin{abstract}
Precisely quantitative assessments of stream flow response to climatic change and permafrost thawing are highly challenging and urgent in cold regions. However, due to the notably harsh environmental conditions, there is little field monitoring data of runoff in permafrost regions, which has limited the development of physically based models in these regions. To identify the impacts of climate change in the runoff process in the Three-River Headwater Region (TRHR) on the Qinghai-Tibet Plateau, two artificial neural network (ANN) models, one with three input variables (previous runoff, air temperature, and precipitation) and another with two input variables (air temperature and precipitation only), were developed to simulate and predict the runoff variation in the TRHR. The results show that the three-input variable ANN model has a superior real-time prediction capability and performs well in the simulation and forecasting of the runoff variation in the TRHR. Under the different scenarios conditions, the forecasting results of ANN model indicated that climate change has a great effect on the runoff processes in the TRHR. The results of this study are of practical significance for water resources management and the evaluation of the impacts of climatic change on the hydrological regime in long-term considerations.
\end{abstract}

\section{Introduction}

Worldwide hydrological processes have been significantly affected by climate change. Rivers in permafrost regions are considered more sensitive to climatic warming than those in other regions [1]. There is significant complexity in physical interactions between thermal, hydrological, and hydrogeological effects in permafrost-affected regions [2]. Thus, the synergic influences of climate and permafrost degradation have resulted in changes in the original rainfallrunoff relationships and runoff generation mechanisms in permafrost regions $[3,4]$. The main feature of the long-term fluctuations in discharge of most Arctic rivers is an increase [5]. The is followed by seasonal variations of river flow with increases in winter discharge and changes in magnitude of minimum river flow and the temporal shifts in maximum river flow $[6,7]$. Conversely, the long-term variation trend in runoff in the permafrost areas of the Qinghai-Tibet Plateau is a decrease [8]. Because of the minor human intervention (e.g., reservoirs, dams, and agricultural irrigation), the main reason for these tendencies is regional changes in climate conditions during the last 30 years [5, 9]. However, little is known about the differences in the effects of climate changes on surface runoff in different permafrost regions $[4,7]$.

The development of hydrological modeling techniques is still progressing in a bid to achieve better accuracy and understanding [10-12]. To quantitatively and accurately analyze series of spatially variable hydrological behaviors and impacts of natural climatic fluctuations and human activities, many physics-based distributed hydrological models have been developed in the last 20 years. However, these distributed hydrological models were restricted in some ungauged basins, especially in cold basins on the Tibetan Plateau, due to the limited availability of data and the lack of knowledge regarding how the freeze-thaw cycle affects runoff generation and dynamics [13]. The frozen layers act 
as special regional aquiclude or aquitard layers and block or weaken the hydraulic connections between the surface water and groundwater, which make the hydrological cycle complex [4,14-16]. Therefore, we still have no effective mathematical method or theory for modeling the hydrogeological processes of the permafrost region $[3,4,17]$. Under complex hydrological processes and data-scarce conditions, the use of physically based models is highly restricted. Thus, the lumped conceptual model is usually used in these regions.

In the last two decades, Artificial Intelligence (AI) has exhibited significant progress in forecasting and modeling nonlinear hydrological applications and in capturing the noise complexity in the data set [18]. At the same time, the most widely employed AI approaches that are artificial neural networks (ANNs) [19], decision tree, and kernel methods such as the Support Vector Machine (SVM) [20], fuzzy logic approach [21], Evolutionary Computation (EC) [22], and wavelet conjunction models [23] also exhibit numerous successful hydrological processes in the hydrological research field [18]. The artificial neural network (ANN) model, a commonly used approach of feed-forward hierarchical architecture, has been successfully applied in the forecasting and modeling of evaporation [24], water quality [25], sediment transport [26], rainfall [27], stream flows [28], groundwater level changes [29-32], and glacier volume [33, 34]. Unlike physically based numerical models, ANNs do not require a detailed knowledge of the physical characteristics of a catchment and have the ability to derive meaning from complicated or imprecise data [35]. This is very convenient when the physical model is not explicitly known or if it cannot be quantified accurately. Most of all, many scholars have used ANN models to simulate and predict runoff fluctuations [36-41]. However, all of these research areas are arid or semiarid areas without permafrost. There are few studies using ANN models to predict runoff in permafrost regions. Meanwhile, due to the cold climate and harsh conditions in study region, getting the measured data is relatively difficult [42]. ANN models can provide a way to reveal the character of hydrological processes, which will help us to better understand the influence of environmental changes on the hydrological processes in permafrost regions with little available data. Therefore, in this study, an ANN model is used to simulate and forecast runoff variations of permafrost regions on the Qinghai-Tibet Plateau (QTP) in China.

The Three-River Headwaters Region (TRHR) in the hinterland of the QTP is the source region of the Yangtze River, Yellow River, and Lantsang River and is known as "China's Water Tower." This region is divided into three subregions: the Yangtze River Headwater Region (YARHR), the Yellow River Headwater Region (YERHR), and the Lantsang River Headwater Region (LARHR). This region is not only an important ecological barrier in China and Eastern Asia but also a region with a sensitive and fragile ecological environment [43]. The warming climate has attracted the attention of researchers to shrinking glaciers, permafrost degradation, and the deterioration of ecosystems on the QTP [44-46]. In the 40 years from 1965 to 2005, the temperature of the TRHR increased, the runoff of the three subregions decreased, and both parameters experienced abrupt changes in 1994, despite the lack of significant changes in precipitation $[47,48]$. Since 2005, runoff values in the YERHR and LARHR have been decreasing continually; however, an increasing trend has been reported in the YARHR $[49,50]$. The impacts of climatic change on runoff have not been the same in the three subregions of the TRHR. Qian et al. [51] investigated the impacts of climate change on annual runoff in the YARHR during 1957-2009 and indicated that the correlation between runoff and climatic components depends on periods. However, the cause and future trend of these runoff changes in the "China's Water Tower" are unknown. For insight into the impacts of climate change and permafrost degradation on the regional water cycle, it is imperative to understand the runoff dynamics in the TRHR under these conditions. Using extensive field monitoring data from the hydrological stations of the TRHR in this research, we attempt to (1) construct a runoff model by using an ANN framework and examine the validity of the model, (2) investigate the impacts of climate change on the runoff dynamics and their differences among the different watershed, and (3) predict the trend of runoff changes in the TRHR in the future under different climate change scenarios.

\section{Study Area Description}

The "Three-River Headwaters" region lies in the interior of the Qinghai-Tibet Plateau in the western part of China and in southern Qinghai province $\left(31^{\circ} 39^{\prime} \mathrm{N}-36^{\circ} 12^{\prime} \mathrm{N}\right.$; $\left.89^{\circ} 45^{\prime} \mathrm{E}-102^{\circ} 23^{\prime} \mathrm{E}\right)$. The study area covers an area of $30.25 \times$ $10^{4} \mathrm{~km}^{2}$, of which more than $67 \%$ contains permafrost, and accounts for approximately $12 \%$ of the total land area of the Qinghai-Tibet Plateau. The TRHR includes the Yangtze River Headwater Region (YARHR), Yellow River Headwater Region (YERHR), and Lantsang River Headwater Region (LARHR). The elevation in the TRHR ranges from 2610 to $6950 \mathrm{~m}$, and the average elevation is $4500 \mathrm{~m}$ [51]. The climate in the study area is the typical plateau continental monsoon type, with an annual mean temperature range from -5.38 to $4.14^{\circ} \mathrm{C}$ and an annual precipitation between 262.2 and $772.8 \mathrm{~mm}[50,52]$.

\section{Materials and Methods}

3.1. Data Collection. In the study region, monthly runoff data were collected from the Changdu, Zhimenda, and Tangnaihai hydrological station located at the outlet of the YERHR, YARHR, and LARHR, respectively. Detailed information on the three hydrological stations can be found in Figure 1 and Table 1 . The monthly mean runoff values from 1961 to 2007 were obtained from the Hydrology and Water Resources Management Bureau of Qinghai Province. Generally, the air temperature and precipitation are considered the main driving forces of runoff variation. There are eighteen weather stations in the TRHR. Most of them were installed between 1958 and 1961. Based on the uniformity, stability, completeness, and consistency of the climate sequences, twelve weather stations were selected in this study. The monthly mean temperature and precipitation data of the selected weather stations were downloaded from the China Meteorological 
TABLE 1: Detailed information of the 12 meteorological stations in the TRHR.

\begin{tabular}{|c|c|c|c|c|c|}
\hline Basin & WTO number & Station & Long. (E) & Lat. (N) & Altitude $(\mathrm{m})$ \\
\hline \multirow{5}{*}{ YARHR } & 56034 & Qingshuihe & $97^{\circ} 08^{\prime}$ & $33^{\circ} 48^{\prime}$ & 4422 \\
\hline & 56021 & Qumalai & $95^{\circ} 47^{\prime}$ & $34^{\circ} 07^{\prime}$ & 4197 \\
\hline & 56004 & Tuotuohe & $92^{\circ} 26^{\prime}$ & $34^{\circ} 12^{\prime}$ & 4542 \\
\hline & 52908 & Wudaoliang & $93^{\circ} 04^{\prime}$ & $35^{\circ} 13^{\prime}$ & 4622 \\
\hline & 56029 & Yushu & $97^{\circ} 05^{\prime}$ & $33^{\circ} 00^{\prime}$ & 3637 \\
\hline \multirow{2}{*}{ LARHR } & 56018 & Zaduo & $95^{\circ} 17^{\prime}$ & $32^{\circ} 53^{\prime}$ & 4074 \\
\hline & 56125 & Nangqian & $96^{\circ} 29^{\prime}$ & $32^{\circ} 12^{\prime}$ & 3656 \\
\hline \multirow{5}{*}{ YERHR } & 56046 & Henan & $101^{\circ} 36^{\prime}$ & $34^{\circ} 44^{\prime}$ & 3529 \\
\hline & 56065 & Dari & $99^{\circ} 39^{\prime}$ & $33^{\circ} 45^{\prime}$ & 3989 \\
\hline & 56067 & Jiuzhi & $101^{\circ} 29^{\prime}$ & $33^{\circ} 25^{\prime}$ & 3631 \\
\hline & 56033 & Maduo & $98^{\circ} 12^{\prime}$ & $34^{\circ} 54^{\prime}$ & 4272 \\
\hline & 52943 & Xinghai & $99^{\circ} 59^{\prime}$ & $35^{\circ} 35^{\prime}$ & 3305 \\
\hline
\end{tabular}

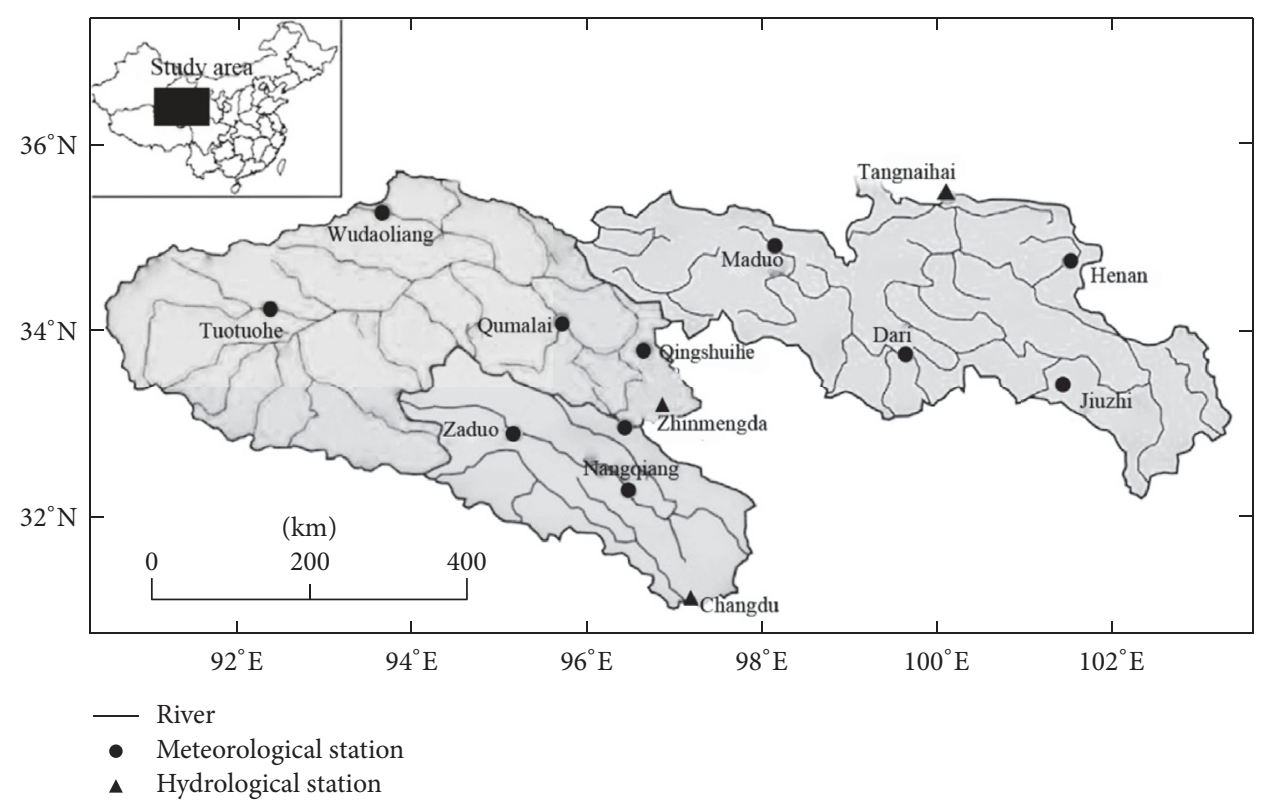

FIGURE 1: Distribution of meteorological stations, hydrological stations, and subregions in the TRHR.

Data Sharing Service System (http://data.cma.cn). The location, WMO number, latitude, longitude, and elevation of the twelve weather stations are presented in Table 2. To ensure consistent runoff data sequences, the temperature and precipitation data covering a range from January 1961 to December 2007 were selected for use in this study.

\subsection{Development of an ANN-Based Runoff Forecasting Model.} The development of an ANN model includes three stages: (1) setting up a typical three-layered feed-forward neural network and determining the connection weights and the activation function, (2) selecting an algorithm (usually the Levenberg-Marquardt training algorithm is used in current research) that provides the best fit to the data to train the ANN model, and (3) identifying the optimal number of neurons in the hidden layer by using a trial and error procedure by varying the number of hidden neurons from 2 to 25. Furthermore, minimum root mean square error is also used to identify the optimal network architecture. Based on these methods, an ANN model is developed in this study to reproduce the dynamic processes of the runoff in the TRHR for the period corresponding to the observed time series of the external variables.

The selection of appropriate input parameters is a very important aspect of ANN modeling because it provides the basic information about the system being modeled. Statistical procedures were suggested for appropriate input vectors for a model $[53,54]$. At present, the phase space reconstruction method and partial autocorrelation function method are generally considered as the two target optimum methods to be commonly used to determine the number of antecedents of parameters in ANN model. In using the phase space reconstruction method, it is very difficult to appropriately determine the parameters of time delay and embedding dimension in this study area. Therefore, in this study, a partial autocorrelation function (PACF) was employed to 
TABLE 2: Detailed information of the three hydrological stations in the TRHR.

\begin{tabular}{lccccc}
\hline Basin & Station & Long. $(\mathrm{E})$ & Lat. $(\mathrm{N})$ & Altitude $(\mathrm{m})$ & ${\text { Drainage area }\left(\mathrm{km}^{2}\right)}^{2}$ \\
\hline YARHR & Zhimenda & $97^{\circ} 14^{\prime}$ & $33^{\circ} 00^{\prime}$ & 3536 & 137,704 \\
LARHR & Changdu & $97^{\circ} 11^{\prime}$ & $31^{\circ} 08^{\prime}$ & 3224 & 50,608 \\
YERHR & Tangnaihai & $100^{\circ} 08^{\prime}$ & $35^{\circ} 30^{\prime}$ & 2725 & 121,972 \\
\hline
\end{tabular}

TABLE 3: Statistical parameters of runoff data in each data set.

\begin{tabular}{lccccccc}
\hline Rivers & & Min & Max & Std & Mean & $C_{\mathrm{s}}$ & $C_{\mathrm{v}}$ \\
\hline \multirow{3}{*}{ YARHR } & All & 46.1 & 2530 & 415.42 & 398.9 & 1.57 & 1.04 \\
& Training & 47.4 & 2130 & 419.87 & 398.2 & 1.56 & 1.05 \\
& Testing & 46.1 & 2530 & 403.59 & 401.1 & 1.64 & 1.01 \\
LARHR & All & 75.9 & 2110 & 399.77 & 468.8 & 0.85 \\
& Training & 75.9 & 2110 & 409.11 & 473.0 & 1.29 & 1.35 \\
& Testing & 94.3 & 1760 & 372.27 & 456.3 & 1.06 \\
YERHR & All & 87.1 & 3550 & 520.63 & 638.3 & 0.86 \\
& Training & 116.0 & 3550 & 548.06 & 675.6 & 1.52 \\
& Testing & 87.1 & 2290 & 413.55 & 529.4 & 0.82 \\
\hline
\end{tabular}

Note. Min is the minimum runoff, Max is the maximum runoff, Std is the standard deviation, $C_{\mathrm{s}}$ is the coefficient of skew, and $C_{\mathrm{v}}$ is the coefficient of variation.

determine the number of parameters corresponding to different values of the monthly runoff antecedents. PACFs are generally used to diagnose the order of an autoregressive process and can be employed in prediction modeling [53]. In this study, to obtain a better prediction result and considering the difficulty of data acquisition in this study region, twelve previous lags were considered as inputs to the models in this study. The inputs represent the previous runoff $(t, t-1, t-2, t-3, t-4, t-5, t-6, t-7, t-8, t-9, t-10$, and $t-11)$, and the output layer node corresponds to the runoff at time $t+1$. Thus, the following combinations of output data for the runoff were evaluated: (1) $\mathrm{RO}_{t+1}$; (2) $\mathrm{RO}_{t+3}$; (3) $\mathrm{RO}_{t+6}$; (4) $\mathrm{RO}_{t+12}$; and (5) $\mathrm{RO}_{t+24}$. The other input parameters for the ANN model were selected by considering the parameters that have the potential to affect the runoff. Air temperature and precipitation, two important factors that generally influence the runoff processes, are inevitably potential input parameters. To correspond to the monthly runoff data, the input variables of precipitation $(P)$ and temperature $(T)$ are as follows: $P_{t}, P_{t-1}, P_{t-2}, P_{t-3}, P_{t-4}, P_{t-5}, P_{t-6}, P_{t-7}, P_{t-8}, P_{t-9}, P_{t-10}$, and $P_{t-11}, \quad$ and $T_{t}, T_{t-1}, T_{t-2}, T_{t-3}, T_{t-4}, T_{t-5}, T_{t-6}, T_{t-7}, T_{t-8}$, $T_{t-9}, T_{t-10}$, and $T_{t-11}$, respectively.

In this study, we developed the ANN model in two ways, one using three driving factors of the monthly mean air temperature, precipitation, and the previous monthly runoff and another using only two driving factors of the monthly mean air temperature and precipitation. The latter was designed for application in the absence of prior runoff data. The detailed methodology of ANN model development and application was similar to that outlined by Chang et al. [32]. The performances of the models developed in this study were assessed using standard statistical performance evaluation criteria, including the coefficient of correlation $(R)$, root mean squared error (RMSE), mean absolute error (MAE), relative root mean squared error (RRMSE), and Nash-Sutcliffe (NS) efficiency coefficient [18]. The methodology of those criteria calculation and development of the simulation models also references Chang et al. [32]. ANN analyses were performed using MATLAB Neural Network Toolbox.

3.3. Data Analysis. All data types (including the monthly average precipitation, monthly average temperature, and monthly average runoff data) used to predict the runoff cover 47 years, which can be regarded as 564 sets of data. All data were divided into two parts as training and testing periods. The first 420 sets of data (1961/01-1995/12) were used for training of the ANN models, and the last 144 sets of data (1996/01-2007/12) were employed for testing. Table 3 shows the statistics of the training, testing, and total data sets for the monthly runoff of the YERHR, YARHR, and LARHR. The recorded monthly maximum runoff was 2530, 2110, and $3550 \mathrm{~m}^{3} / \mathrm{s}$ for the YARHR, LARHR, and YERHR, respectively. The monthly minimum runoff was 46.1, 75.9 , and $116.0 \mathrm{~m}^{3} / \mathrm{s}$ for the YARHR, LARHR, and YERHR, respectively. The observed monthly runoff values show low positive skewness for all stations, showing that the data have a less scattered distribution.

\section{Results}

4.1. ANN Model with Three Input Factors. By using the monthly average temperature, monthly average precipitation, and previous monthly average runoff as driving factors, the performances of the ANN models for forecasting the 1-, 3-, 6-, 12- and 24-month-ahead runoff variations for the YERHR, YARHR, and LARHR are summarized in Tables 4,5 , and 6 , respectively. During the testing periods, the performances of the 1-, 12-, and 24-month-ahead forecasting models are better than those of the 3- and 6-monthahead forecasts. In YARHR and LARHR, the NS and $R$ of the forecasting models are more than 0.8 and 0.9 for the 
TABLE 4: Performance statistics of the ANN model with three input variables (runoff, precipitation, and air temperature) during the training and testing periods for 1-, 6-, 12-, and 24-month-ahead runoff forecasting in the YARHR.

\begin{tabular}{|c|c|c|c|c|c|c|c|c|c|}
\hline & \multicolumn{4}{|c|}{ Training periods } & \multirow{2}{*}{ Structure } & \multicolumn{4}{|c|}{ Testing periods } \\
\hline & $R$ & RMSE & MAE & NS & & $R$ & RMSE & MAE & NS \\
\hline 1 month ahead & 0.9301 & 153.25 & 90.67 & 0.8644 & $36-14-1$ & 0.9161 & 165.65 & 91.20 & 0.8389 \\
\hline 3 months ahead & 0.8794 & 198.44 & 118.41 & 0.7726 & $36-2-1$ & 0.8806 & 196.28 & 102.95 & 0.7745 \\
\hline 6 months ahead & 0.8551 & 216.04 & 125.40 & 0.7304 & $36-4-1$ & 0.8708 & 205.58 & 113.44 & 0.7569 \\
\hline 12 months ahead & 0.8744 & 199.57 & 123.82 & 0.7637 & $36-2-1$ & 0.9064 & 180.00 & 116.37 & 0.8184 \\
\hline 24 months ahead & 0.8632 & 204.97 & 122.33 & 0.7385 & $36-9-1$ & 0.9078 & 190.50 & 112.12 & 0.8063 \\
\hline
\end{tabular}

TABLE 5: Performance statistics of the ANN model with three input variables (runoff, precipitation, and air temperature) during the training and testing periods for 1-, 6-, 12-, and 24-month-ahead runoff forecasting in the LARHR.

\begin{tabular}{|c|c|c|c|c|c|c|c|c|c|}
\hline & \multicolumn{4}{|c|}{ Training periods } & \multirow{2}{*}{ Structure } & \multicolumn{4}{|c|}{ Testing periods } \\
\hline & $R$ & RMSE & MAE & NS & & $R$ & RMSE & MAE & NS \\
\hline 1 month ahead & 0.9258 & 155.20 & 89.26 & 0.8550 & $36-8-1$ & 0.9294 & 139.77 & 88.29 & 0.8618 \\
\hline 3 months ahead & 0.8745 & 199.75 & 121.41 & 0.7599 & $36-22-1$ & 0.8770 & 182.44 & 116.27 & 0.7651 \\
\hline 6 months ahead & 0.8660 & 204.15 & 127.06 & 0.7495 & $36-2-1$ & 0.8918 & 171.69 & 107.40 & 0.7944 \\
\hline 12 months ahead & 0.8828 & 185.90 & 110.92 & 0.7792 & $36-7-1$ & 0.9032 & 168.58 & 102.40 & 0.8058 \\
\hline 24 months ahead & 0.8393 & 212.27 & 134.84 & 0.7037 & $36-7-1$ & 0.8946 & 168.76 & 106.36 & 0.8003 \\
\hline
\end{tabular}

TABLE 6: Performance statistics of the ANN model with three input variables (runoff, precipitation, and air temperature) during the training and testing periods for 1-, 6-, 12-, and 24-month-ahead runoff forecasting in the YERHR.

\begin{tabular}{|c|c|c|c|c|c|c|c|c|c|}
\hline & \multicolumn{4}{|c|}{ Training periods } & \multirow{2}{*}{ Structure } & \multicolumn{4}{|c|}{ Testing periods } \\
\hline & $R$ & RMSE & MAE & NS & & $R$ & RMSE & MAE & NS \\
\hline 1 month ahead & 0.9204 & 213.00 & 121.90 & 0.8470 & $36-4-1$ & 0.8892 & 196.46 & 123.23 & 0.7852 \\
\hline 3 months ahead & 0.8516 & 304.90 & 171.41 & 0.6866 & $36-2-1$ & 0.8021 & 253.93 & 153.49 & 0.6421 \\
\hline 6 months ahead & 0.7835 & 356.27 & 207.98 & 0.5717 & $36-2-1$ & 0.7860 & 267.58 & 176.19 & 0.6091 \\
\hline 12 months ahead & 0.8232 & 312.27 & 191.50 & 0.6699 & $36-3-1$ & 0.8047 & 258.95 & 158.42 & 0.6453 \\
\hline 24 months ahead & 0.7780 & 349.42 & 207.56 & 0.5747 & $36-4-1$ & 0.8004 & 267.50 & 180.98 & 0.6307 \\
\hline
\end{tabular}

12- and 24-month-ahead forecasts, respectively. While the $R$ is more than 0.8 , the NS is more than 0.63 in YERHR. Those results showed that the ANN model with three input driving factors has excellent validity for the relatively long-term 12 or 24-month-ahead forecasts. The RMSE and MAE values, less than $267.58 \mathrm{~m}^{3} / \mathrm{s}$ and $180.98 \mathrm{~m}^{3} / \mathrm{s}$, respectively, show the valuable and appropriate simulation capacity of the ANN model. Normally, a model can be claimed to produce a perfect and accurate estimate if the NS criterion is greater than 0.8 , and the modeling result is acceptable when NS is $\geq 0.6$ but $\leq 0.8$ [55]. The NS values in this study for 1-, 12-, and 24month-ahead forecasts are all over 0.8 in the YARHR and LARHR, and the NS values for 1-, 12-, and 24-month-ahead forecasts in the YERHR are all over 0.63 , which indicates that the models produce acceptable results (Tables 4, 5, and 6). On the whole, the ANN model with the three driving factors of temperature, precipitation, and previous runoff has more forecasting validity in the YARHR and the LARHR than in the YERHR.

The runoff values predicted using the ANN model developed above were compared with field-observed data from the YERHR, YARHR, and LARHR for the 6- and 12month-ahead forecasts, as shown in Figure 2. The correlation coefficient $R^{2}$ is greater than 0.83 for the YARHR, greater than 0.80 for the LARHR, and greater than 0.62 for the YERHR, indicating that the runoff values estimated by the ANN forecasting models closely matched the observed values and followed the same dynamic trend. For the relatively longterm 24-month forecast, the developed ANN model could identify the varying processes in the runoff that fit better with the measured variation of the runoff during the wet season and dry season (Figure 3). However, the prediction accuracy of the extreme flood runoff in the wet season was fair with significant underestimation (Figure 3). Under the condition of not considering the underestimation for one of the most extreme flood flows during 24 months, the RRMSE values of ANN prediction model in this study for 1-, 3-, 6-, $12-$, and 24-month-ahead forecasts in the YARHR are $16.84 \%$, $19.89 \%, 22.88 \%, 19.17 \%$, and $23.37 \%$, respectively. At the same condition, the RRMSE values of ANN prediction model in this study for 1-, 3-, 6-, 12-, and 24-month-ahead forecasts in the LARHR are $15.23 \%, 19.06 \%, 17.54 \%, 16.33 \%$, and $20.45 \%$, respectively, and $23.64 \%, 23.98 \%, 27.81 \%, 28.03 \%$, and $28.96 \%$, respectively, in the YERHR. The result of relative root mean square error (RRMSE) also showed that the results of simulation about the month runoff in the YARHR and 

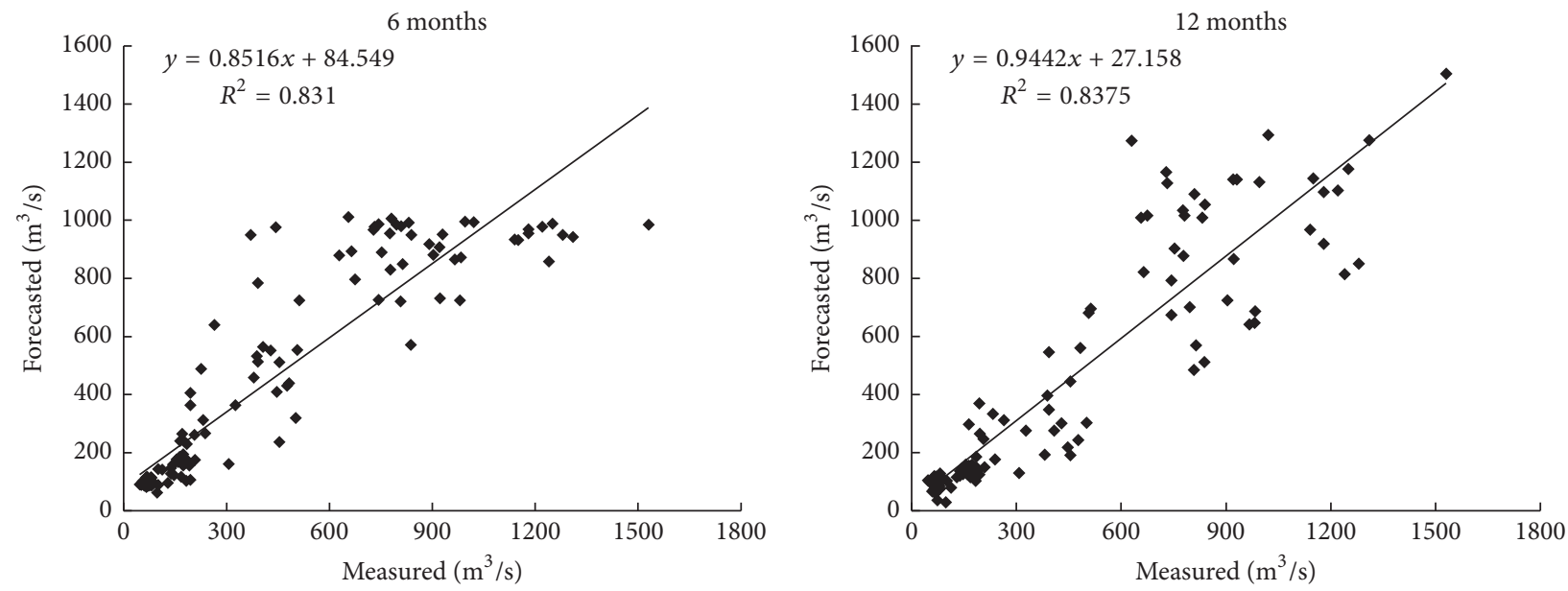

(a)
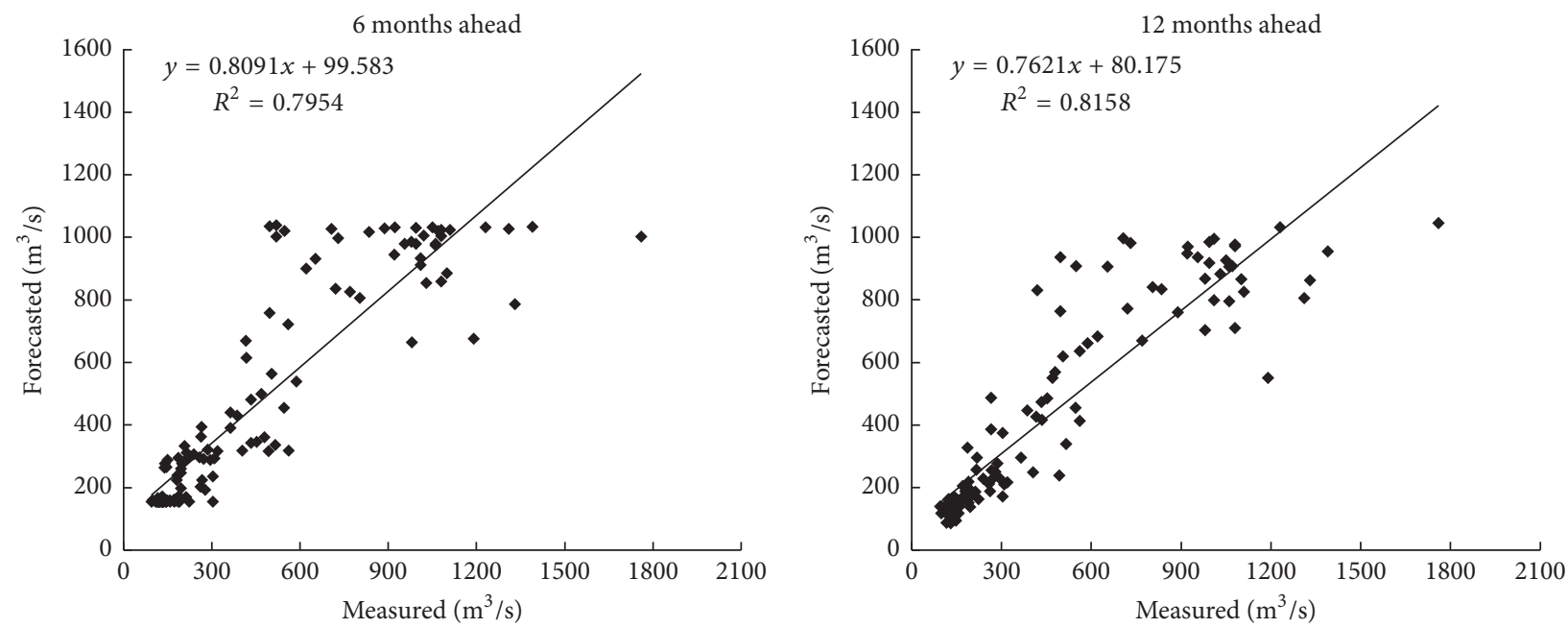

(b)
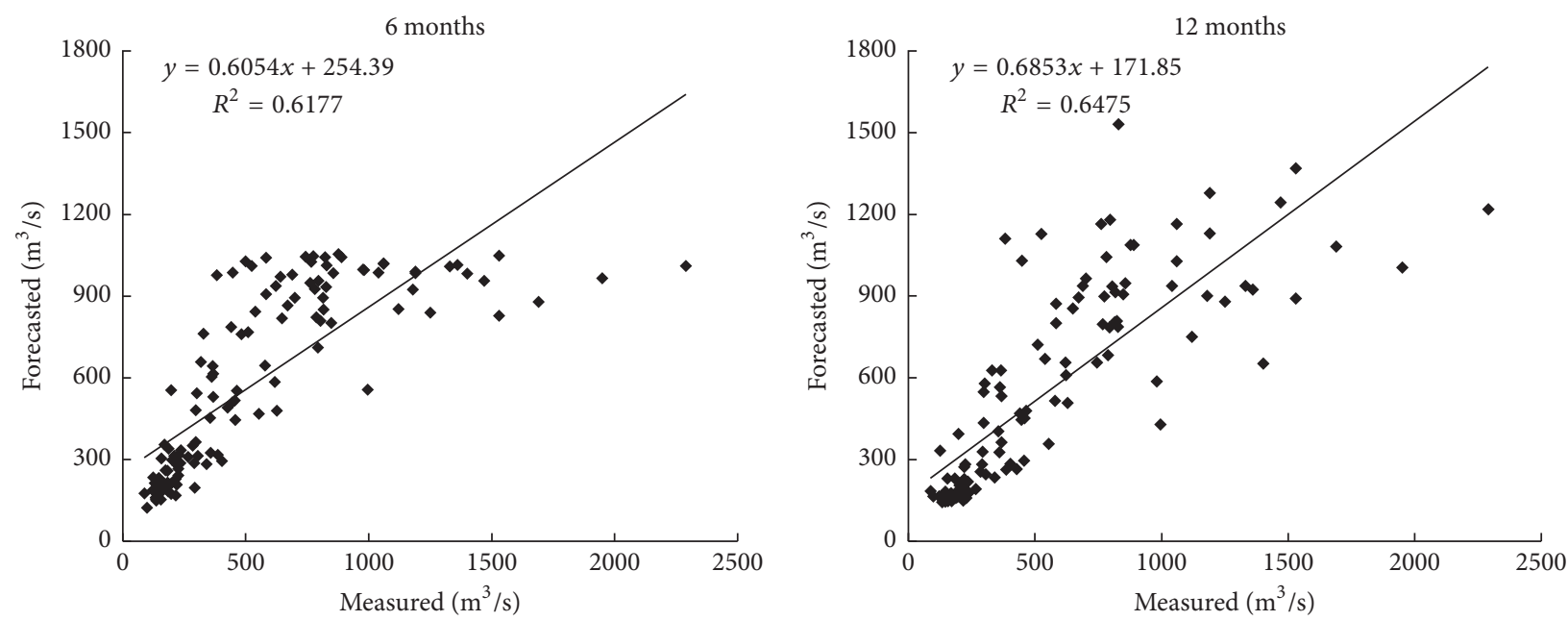

(c)

FIGURE 2: Comparison of the measured runoff values and those forecasted 6 and 12 months ahead by the ANN model for the YARHR (a), the LARHR (b), and the YERHR (c). 


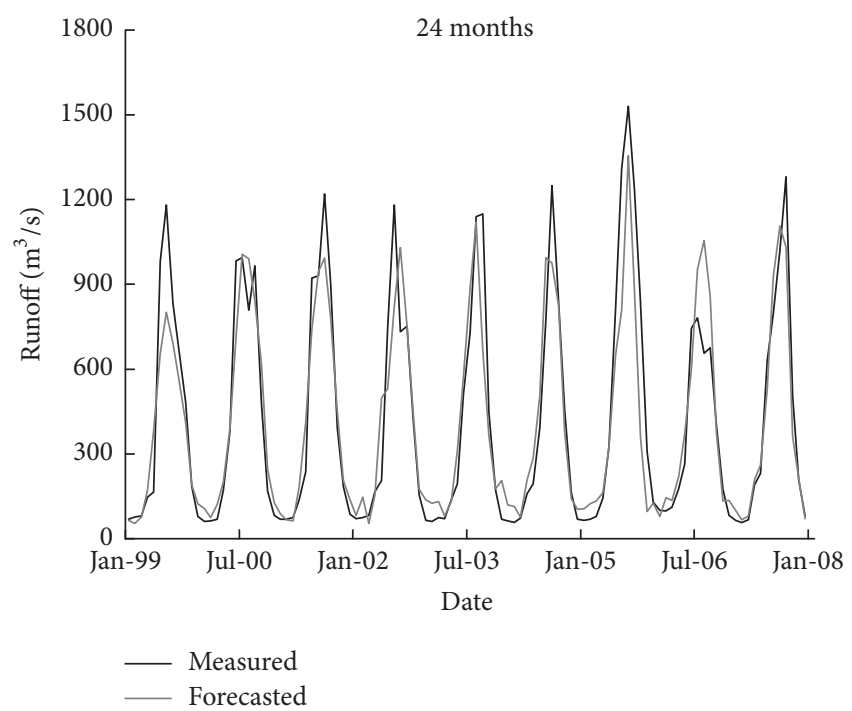

(a)

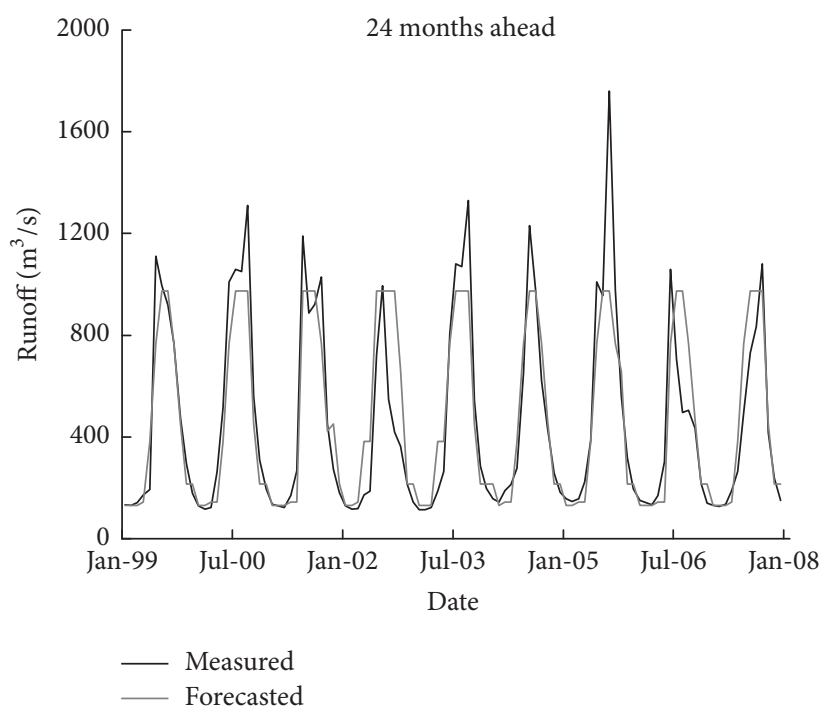

(b)

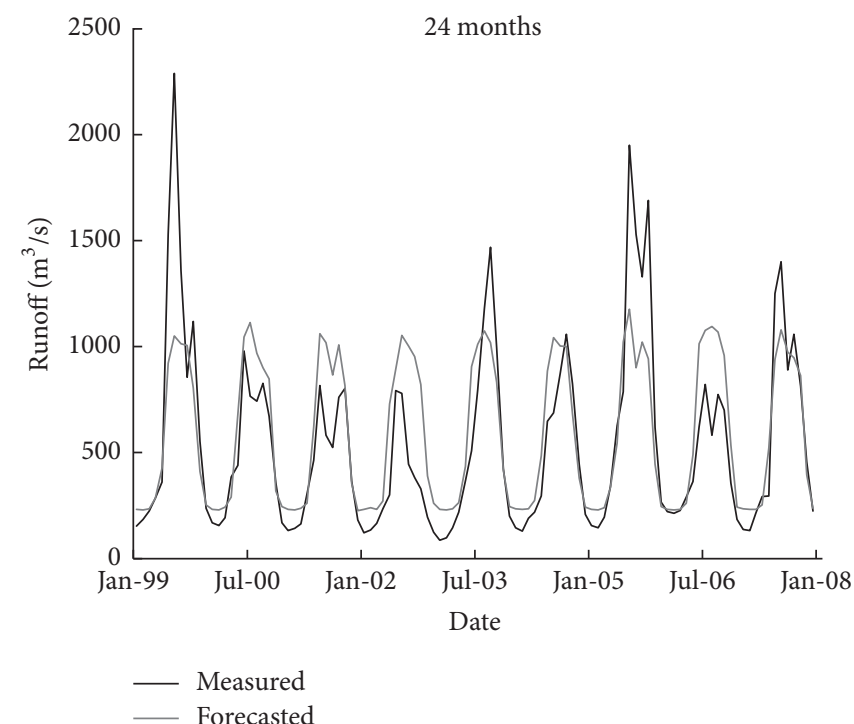

(c)

FIgURE 3: Comparison of the measured runoff values and those forecasted 24 months ahead by the ANN model for the YARHR (a), the LARHR (b), and the YERHR (c).

LARHR are superior to the simulation results in the YERHR (Tables 4-9). Therefore, the ANN forecasting model with three driving factors developed in this study could provide accurate and reliable monthly runoff predictions for a period as long as two years, although the prediction accuracy of the highest amount of flood runoff in the wet season was not better than that of the minimum amount of base runoff in the dry season (there are small underestimations of flood runoff by the ANN model).

4.2. ANN Model with the Two Factors: Temperature and Precipitation. The above results show that the ANN model with three driving factors (temperature, precipitation, and previous runoff) developed in this study has validity and reliability in simulating and predicting runoff variation. However, observed runoff data is lacking in most permafrost regions, whereas the climate factors of temperature and precipitation are relatively easy to obtain. Thus, if the ANN model developed above could be executed using only climate factors to predicate the dynamic trends in the runoff, the model would have even higher application value in permafrost regions. Based on the ANN model developed above, the previous runoff factor was removed from the original three driving factors, so that the input variables are precipitation $(P)$ and temperature $(T)$.

When the input variables are the mean monthly temperature $(T)$ and monthly precipitation $(P)$, the performances of the ANN models for forecasting the 1-, 3-, 6-, 12-, and 24-month-ahead runoff dynamics for the three rivers in the TRHR are shown in Tables 7, 8, and 9. The $R$ values in the testing period for the three rivers were almost all above 0.78, showing the good correlation between the observed 
TABLE 7: Performance of the ANN model with two input variables (precipitation and air temperature) during the training and testing periods for 1-, 3-, 6-, 12-, and 24-month-ahead runoff forecasting in the YARHR.

\begin{tabular}{lccccccrrr}
\hline & \multicolumn{4}{c}{ Training periods } & \multicolumn{2}{c}{ Testing periods } \\
& $R$ & RMSE & MAE & NS & Structure & $R$ & RMSE & MAE & NS \\
\hline 1 month ahead & 0.9132 & 170.44 & 99.15 & 0.8322 & $24-5-1$ & 0.9163 & 175.22 & 98.64 & 0.8306 \\
3 months ahead & 0.8696 & 207.50 & 121.73 & 0.7514 & $24-8-1$ & 0.8625 & 215.22 & 119.73 & 0.7435 \\
6 months ahead & 0.8905 & 189.52 & 109.08 & 0.7925 & $24-2-1$ & 0.8848 & 198.98 & 120.18 & 0.7814 \\
12 months ahead & 0.8616 & 209.13 & 111.00 & 0.7406 & $24-2-1$ & 0.9107 & 179.52 & 100.22 & 0.8214 \\
24 months ahead & 0.8708 & 197.48 & 118.60 & 0.7573 & $24-9-1$ & 0.8994 & 196.42 & 100.03 & 0.7941 \\
\hline
\end{tabular}

TABLE 8: Performance of the ANN model with two input variables (precipitation and air temperature) during the training and testing periods for 1-, 3-, 6-, 12-, and 24-month-ahead runoff forecasting in the LARHR.

\begin{tabular}{|c|c|c|c|c|c|c|c|c|c|}
\hline & \multicolumn{4}{|c|}{ Training periods } & \multirow{2}{*}{ Structure } & \multicolumn{4}{|c|}{ Testing periods } \\
\hline & $R$ & RMSE & MAE & NS & & $R$ & RMSE & MAE & NS \\
\hline 1 month ahead & 0.9012 & 178.84 & 113.54 & 0.8074 & $24-11-1$ & 0.9334 & 140.04 & 101.72 & 0.8709 \\
\hline 3 months ahead & 0.8818 & 192.94 & 119.02 & 0.7760 & $24-14-1$ & 0.8947 & 174.09 & 110.11 & 0.8002 \\
\hline 6 months ahead & 0.8682 & 202.71 & 121.35 & 0.7530 & $24-3-1$ & 0.9090 & 164.47 & 101.60 & 0.8243 \\
\hline 12 months ahead & 0.8802 & 187.92 & 121.19 & 0.7744 & $24-5-1$ & 0.9223 & 154.56 & 105.45 & 0.8424 \\
\hline 24 months ahead & 0.8773 & 187.17 & 118.25 & 0.7696 & 24-6-1 & 0.9043 & 162.19 & 105.65 & 0.8156 \\
\hline
\end{tabular}

and forecasted runoff using the ANN model derived from only the monthly mean temperature and monthly average precipitation. The RMSE and MAE were less than $274.90 \mathrm{~m}^{3} / \mathrm{s}$ and $177.19 \mathrm{~m}^{3} / \mathrm{s}$, respectively. Meanwhile, the NS values are all over 0.60 . Those statistical indices showed the forecasting validity and reliability of the ANN model with two input variables. In addition, the performances of the 12- and 24month-ahead forecast are better than those of the 3- and 6-month-ahead forecasts for all the three rivers (Tables 7 , 8 , and 9). This result is consistent with the results of the ANN model with the three input factors discussed above. The efficiency of the forecasting model of two input parameters (precipitation and temperature) is similar to the forecasting model efficiency of the three input parameters (temperature, precipitation, and previous runoff). These results show that the longer-term (12 and 24 months) dynamics of the runoff were relatively stable using the ANN forecasting model.

The statistical indices of the forecasting results for the YARHR and LARHR were better than those of the YERHR, which shows that the runoff dynamics in the YARHR and the LARHR were more obviously affected by climate factors (air temperature and precipitation) than those in the YERHR. The effects of air temperature and precipitation explain more than $90 \%$ of the variation in the runoff 24 months ahead in the YARHR and the LARHR and more than $79 \%$ of the variation in the runoff 24 months ahead in the YERHR. Therefore, the ANN forecasting model developed in this study using easily obtainable climate data could offer valid and reliable predications of the monthly runoff variation.

4.3. Response of Runoff to Climate Change. Over the last 10 years, the air temperature has increased by $0.47^{\circ} \mathrm{C} / 10$ years, while the precipitation has increased slightly in the headwaters of the Lantsang, Yangtze, and Yellow Rivers. According to this actual climate change, two possible climate change scenarios in the future are assumed as follows: (1) precipitation increases by $10 \%$, while the air temperature increases by $0.5^{\circ} \mathrm{C}, 1.0^{\circ} \mathrm{C}$, or $2.0^{\circ} \mathrm{C}$; (2) precipitation increases by $20 \%$, while the air temperature increases by $0.5^{\circ} \mathrm{C}, 1.0^{\circ} \mathrm{C}$, or $2.0^{\circ} \mathrm{C}$. The runoff responses to the climate changes are then forecasted by using the ANN model established above with the two input parameters of $T$ and $P$ for producing 24-monthahead predictions, and the results are listed in Table 10.

With temperature increases of $0.5,1.0$, and $2.0^{\circ} \mathrm{C}$ and an increase in precipitation of $10 \%$ or $20 \%$, the average runoff in the YARHR would increase by $1.6 \%\left(7.52 \mathrm{~m}^{3} / \mathrm{s}\right)$, $1.5 \%\left(7.41 \mathrm{~m}^{3} / \mathrm{s}\right)$, and $0.9 \%\left(5.43 \mathrm{~m}^{3} / \mathrm{s}\right)$ per year, respectively. The average runoff in the LARHR would increase by $3.4 \%$ $\left(15.51 \mathrm{~m}^{3} / \mathrm{s}\right), 3.4 \%\left(15.61 \mathrm{~m}^{3} / \mathrm{s}\right)$, and $3.5 \%\left(15.81 \mathrm{~m}^{3} / \mathrm{s}\right)$ per year, respectively. The average runoff in the YERHR would increase by $1.1 \%\left(6.13-6.34 \mathrm{~m}^{3} / \mathrm{s}\right)$ under all three climate scenarios.

When the air temperature increases by $0.5,1.0$, and $2.0^{\circ} \mathrm{C}$, the average difference in runoff increase is 20 and $48 \mathrm{~m}^{3} / \mathrm{s}$ when the precipitation increases by $10 \%$, and the difference is 21 and $46 \mathrm{~m}^{3} / \mathrm{s}$ when the precipitation increases by $20 \%$ in the YARHR. Under the same scenarios, the average difference in runoff increase is 0.96 and $2.33 \mathrm{~m}^{3} / \mathrm{s}$ when the precipitation increases by $10 \%$, and the difference is 0.51 and $1.33 \mathrm{~m}^{3} / \mathrm{s}$ when the precipitation increases by $20 \%$ in the LARHR. However, the average difference in runoff variation is -0.33 and $-0.57 \mathrm{~m}^{3} / \mathrm{s}$ when the precipitation increases by $10 \%$, and the difference is -0.7 and $-1.35 \mathrm{~m}^{3} / \mathrm{s}$ when the precipitation increases by $20 \%$ in the YERHR. These results indicate that the response of runoff to climate change (the synergic effects of temperature and precipitation) is more intense and variable in the YARHR than in the LARHR and YERHR. However, even in the YERHR, the runoff would decrease with increasing temperature under a given precipitation scenario.

Future climate change with warming and slight wetting could greatly change the annual runoff of TRHR. In the 
TABLE 9: Performance of the ANN model with two input variables (precipitation and air temperature) during the training and testing periods for 1-, 3-, 6-, 12-, and 24-month-ahead runoff forecasting in the YERHR.

\begin{tabular}{|c|c|c|c|c|c|c|c|c|c|}
\hline & \multicolumn{4}{|c|}{ Training periods } & \multirow{2}{*}{ Structure } & \multicolumn{4}{|c|}{ Testing periods } \\
\hline & $R$ & RMSE & MAE & NS & & $R$ & RMSE & MAE & NS \\
\hline 1 month ahead & 0.8906 & 251.05 & 144.96 & 0.7874 & $24-12-1$ & 0.8841 & 204.16 & 129.12 & 0.7809 \\
\hline 3 months ahead & 0.8329 & 307.64 & 189.14 & 0.6810 & $24-5-1$ & 0.8003 & 263.93 & 165.42 & 0.6322 \\
\hline 6 months ahead & 0.7819 & 354.69 & 210.55 & 0.5755 & $24-2-1$ & 0.7757 & 274.90 & 171.01 & 0.5997 \\
\hline 12 months ahead & 0.7919 & 333.87 & 203.46 & 0.6227 & $24-13-1$ & 0.7978 & 263.63 & 166.32 & 0.6306 \\
\hline 24 months ahead & 0.7707 & 362.16 & 216.94 & 0.5431 & $24-2-1$ & 0.7938 & 271.00 & 177.19 & 0.6209 \\
\hline
\end{tabular}

TABLE 10: The response of runoff to climate change at the Three-River Headwater Regions $\left(\mathrm{m}^{3} / \mathrm{s}\right)$.

\begin{tabular}{|c|c|c|c|c|c|c|c|c|}
\hline \multirow{2}{*}{ Sites } & \multirow{2}{*}{ Index } & \multirow{2}{*}{ Normal } & \multicolumn{3}{|c|}{$P 10 \%$} & \multicolumn{3}{|c|}{$P 20 \%$} \\
\hline & & & T0.5 & $T 1.0$ & $T 2.0$ & T0.5 & $T 1.0$ & T2.0 \\
\hline \multirow{4}{*}{ YARHR } & Average runoff & 416.51 & 471.16 & 498.16 & 561.68 & 478.58 & 505.57 & 567.11 \\
\hline & Max & 1277.95 & 1348.05 & 1374.07 & 1414.78 & 1353.04 & 1370.28 & 1422.16 \\
\hline & Min & 26.88 & 9.89 & 8.13 & 19.44 & 6.48 & 6.75 & 22.24 \\
\hline & Average change & 0 & 91.14 & 111.02 & 158.80 & 101.21 & 122.16 & 168.34 \\
\hline \multirow{4}{*}{ LARHR } & Average runoff & 460.30 & 457.03 & 453.29 & 445.67 & 472.54 & 468.90 & 461.48 \\
\hline & Max & 1098.51 & 1095.30 & 1093.81 & 1090.39 & 1097.25 & 1095.86 & 1092.67 \\
\hline & Min & 123.19 & 123.70 & 124.34 & 126.32 & 124.99 & 125.97 & 130.14 \\
\hline & Average change & 0 & 70.63 & 71.69 & 74.02 & 81.06 & 81.57 & 82.90 \\
\hline \multirow{4}{*}{ YERHR } & Average runoff & 566.75 & 568.95 & 565.84 & 559.67 & 575.08 & 572.04 & 566.01 \\
\hline & Max & 1192.67 & 1214.68 & 1210.26 & 1201.11 & 1239.65 & 1235.57 & 1227.12 \\
\hline & Min & 206.05 & 202.78 & 202.60 & 202.25 & 200.56 & 200.40 & 200.08 \\
\hline & Average change & 0 & 70.37 & 70.04 & 69.47 & 76.31 & 75.61 & 74.26 \\
\hline
\end{tabular}

Note. (1) T0.5, T1.0, and T2.0 mean air temperature increased by $0.5^{\circ} \mathrm{C}, 1.0^{\circ} \mathrm{C}$, and $2.0^{\circ} \mathrm{C}$, respectively. $P 10 \%$ and $P 20 \%$ mean the precipitation increased by $10 \%$ and $20 \%$, respectively.

climate change scenarios involving a precipitation increase, the mean monthly runoff would increase in the TRHR under a given temperature. In the climate change scenarios involving a temperature increase, the mean monthly runoff would increase in the YARHR and LARHR, but the mean monthly runoff would decrease in the YERHR. There are obvious differences in the responses of runoff to climate changes in the different watersheds of the TRHR.

\section{Discussion}

5.1. Validity of the ANN Models Using Two and Three Variables to Predict Runoff. A mathematical model of hydrogeology based on physical mechanisms is certainly a powerful and valid tool for simulating and forecasting variations in runoff processes. The applicability of the runoff model to real situations depends on the accuracy of the input data and the parameters. It is relatively difficult to observe and measure the runoff processes on the Qinghai-Tibet Plateau due to the complex and unknown mechanisms of runoff formation and runoff dynamics. For example, we do not exactly understand the interaction between the surface water and groundwater in the permafrost region, and the uncertainty extends to the permafrost aquifer due to the lack of intense observation data and related theories $[4,32,42]$. Glacier and snow meltwater are the main sources of river runoff on the Qinghai-Tibet Plateau, but a lack of data, parameters, and methods hinders exact simulations of the effects of meltwater on surface runoff [1]. Thus, data-scarce conditions and parameter uncertainty present limitations and formidable challenges to numerical runoff model applicability. Seeking to overcome the data limitations and parameter uncertainty and to simplify the physical assumptions inherent in numerical models, artificial neural networks (ANNs) are considered a good alternative approach for runoff modeling and prediction [36-38]. Our results confirmed that the ANN model and prediction approach can be successfully used to simulate and predict the runoff variation in runoff processes on the Qinghai-Tibet Plateau and can improve our understanding of the response of permafrost runoff to climate change.

To enable the ANN model to achieve excellent predictive accuracy over specific field locations in complex water cycle systems, as many input variables should be used as possible. However, data-scarce conditions and parameter uncertainty present limitations and formidable challenges to numerical runoff model applicability. At present, most researchers have found that three input variables related to accessible field data (i.e., runoff, precipitation, and temperature) were adequate to develop an excellent ANN model [36, 37]. In this study, we developed two ANN models based on three input variables (e.g., runoff, precipitation, and temperature) and two input variables (e.g., precipitation and temperature) for the complex runoff processes of the permafrost region on 
the Qinghai-Tibet Plateau. In comparing Tables 4, 5, and 6 with Tables 7, 8, and 9, it is found that the evaluation criteria (e.g., $R, \mathrm{NS}$, and RMSE) of model performance indicated significant differences between the three input variables' model and the two input variables' model. The forecasting performance of the three input variables' model was only slightly better than that of two input variables' model. Taking the previous runoff as one of the three input variables, the ANN model achieved acceptable predictive accuracy in the TRHR, with $R>0.80$, NS $>0.63$, and RMSE $<267.50$ for the 24-month-ahead prediction. In particular, the ANN model for the three input variables achieved more excellent predictive accuracy in the YARHR and the LARHR, with $R>$ 0.89 , NS $>0.80$, and RMSE $<190.5$ for the 24 -month-ahead prediction (Tables 4, 5, and 6). The results were consistent with most findings related to ANN technology applications worldwide [36, 37]. However, the ANN model using the two input variables of precipitation and air temperature also had a reasonably good prediction of runoff in the TRHR, with $R$ $>0.79$, NS $>0.62$, and RMSE $<271.0$ for the 24 -month-ahead prediction. In particular, the ANN model for the two input variables achieved better predictive accuracy in the YARHR and the LARHR, with $R>0.90$, NS $>0.79$, and RMSE $<215.22$ for the 24-month-ahead prediction (Tables 7, 8, and 9). The forecasts of both the model with three input variables and the model with two input variables in the YARHR and the LARHR were superior.

These results indicate that the previous runoff does not have significant effects on the predicted runoff in the TRHR and that the climate factors had more intense effects on the runoff in the TRHR. In fact, due to the sensitivity and vulnerability of the runoff to climate changes in the permafrost region, the simulation of the runoff must consider the heat transmission and the runoff supply of permafrost degradation. In addition, the impacts of glacier and snow cover responses to climate change on runoff processes also enhanced the effects of the climate factors on the runoff processes in the TRHR.

5.2. Impacts of Climate Change on Runoff. Runoff is intensely affected by the precipitation and the freeze-thaw processes related to snow, ice, and permafrost, which directly control the formation and development of the runoff. In the TRHR, the annual glacier runoff is $15.52,1.74$, and $4.43 \times 10^{8} \mathrm{~m}^{3}$ in the YARHR, YERHR, and LARHR, respectively, and the contribution of glacier meltwater to watershed runoff is $8.8,0.8$, and $4.0 \%$, respectively [56]. With the warming climate, the glacier runoff has significantly increased in the last 30 years [57]. Unlike in nonfrozen regions, the soil freezing process not only confines the water exchange to the land surface, active soil, and permafrost and impedes water movement in the impervious frozen layers but also results in an entropy change process associated with the phase transition of frozen soil moisture. Therefore, there are unique behaviors in the hydrological cycle in permafrost regions $[16,32,42]$. All the environmental features of runoff formation and development demonstrate the high sensitivity and vulnerability of the runoff to climate change in the TRHR.
The sensitivity of runoff to climate change was analyzed by using the ANN model developed in this study, and the results are shown in Table 10. It is found that there was a significant effect of precipitation increases of $10 \%$ and $20 \%$ on the runoff in the YARHR, LARHR, and YERHR, and the forecasted runoff increased in the YARHR, LARHR, and YERHR (Table 10). If the air temperature increases by $0.5,1.0$, and $2.0^{\circ} \mathrm{C}$, the forecasted runoff increases in the YARHR but decreases in the LARHR and YERHR. Higher air temperatures resulted in greater increases in predicted runoff in the YARHR. Even if the air temperature increased by only $0.5^{\circ} \mathrm{C}$, the response of the forecasted runoff was more significant than that with a precipitation increase of $20 \%$ in the YARHR. However, the runoff significantly decreases with climate warming in the LARHR and YERHR. If the precipitation increases only $10 \%$, the water dissipation resulting from a temperature increase of $1.0^{\circ} \mathrm{C}$ or $2.0^{\circ} \mathrm{C}$ not only offsets the additional precipitation but decreased the runoff in the LARHR and YERHR. Because there is relatively greater glacier melt water feeding the runoff in the LARHR than in the YERHR, the runoff significantly increases in the LARHR with warming but decreases in the YERHR when temperature increases more than $2.0^{\circ} \mathrm{C}$ and precipitation increases by $20 \%$ (Table 10 ).

$\mathrm{Xu}$ et al. [58] found that the air temperature will increase by $2^{\circ} \mathrm{C}$ or more and that precipitation will increase by less than $20 \%$ by the 2050 s in the study area. From the predicted results listed in Table 10, the mean annual surface runoff increases with increasing precipitation in the YARHR, LARHR, and YERHR. The mean annual surface runoff decreases with increasing air temperature in the LARHR and YERHR but increases significantly with increasing air temperature in the YARHR. These results were consistent with the findings of runoff responses to climate change in the TRHR [47, 48, 50, 59]. In northern Eurasian and northwestern North American rivers, it was suggested that the accelerated increase in the groundwater discharge from permafrost degradation has led to runoff increases in recent decades $[7,60,61]$. In the permafrost regions of the QinghaiTibet Plateau, Ge et al. [62] also found that, with increased warming, there is more groundwater flow in the active layer and therefore increased groundwater discharge to rivers. Because permafrost covers only $42 \%$ of the YERHR, less than that of the YARHR (76\%) and LARHR (63\%) [1], the increased groundwater in the YERHR is believed to be significantly less than that in the YARHR. Glaciers cover $1895.0 \mathrm{~km}^{2}$ in the YARHR, $316.32 \mathrm{~km}^{2}$ in the LARHR, and only $172.41 \mathrm{~km}^{2}$ in the YERHR [56]. Thus, the glacier meltwater discharge to the river is not greater in the YARHR than that in the LARHR and YERHR at present but will increase with greater glacier runoff under a future warmer climate.

These results demonstrate that climate warming has a great effect on the surface runoff processes on QinghaiTibet Plateau. Only a precipitation increase greater than $20 \%$ could offset the effects of an increase in air temperature of $1.0^{\circ} \mathrm{C}$. The areas of permafrost, glaciers, and snow cover are the important factors in offsetting the effects of climate warming on surface runoff processes. Enhanced runoff from 
glacier and permafrost areas tends to increase runoff under future climate warming. For the TRHR, the predicted results of the ANN model show that the surface runoff has a tendency to decrease in the LARHR and the YERHR when air temperatures rise by $2.0^{\circ} \mathrm{C}$, whereas the surface runoff has a tendency to increase slightly in the YARHR.

\section{Conclusions}

The ANN technology and prediction approach is useful and valid in simulating and forecasting runoff variations to overcome data limitations, parameter uncertainty, and the formidable challenge of numerical hydrological model applicability. For prediction of the runoff in the TRHR, two ANN models were developed in this study. If field observations of the runoff are available, the ANN model with three input variables (runoff, precipitation, and temperature) should be developed and applied in permafrost regions. The three input variables' ANN model has a significantly superior real-time prediction capability and produces a high-accuracy performance in the simulation and forecasting of the runoff dynamics. When no field observations of the runoff are available, the ANN model developed using only two input variables of accessible climate data (precipitation and air temperature) also has a good accuracy for simulation and prediction of the variations in runoff.

The runoff variation and its response to climate change differ for the different rivers on the Qinghai-Tibetan Plateau. The runoff is intensely affected by climate warming changes and has more sensitivity to temperature variation than to precipitation in the YARHR. However, the runoff is more sensitive to precipitation variations than to air temperatures in the LARHR and the YERHR. The predicted results of the ANN model show that the surface runoff will likely decrease in the LARHR and the YERHR by the 2050s, whereas the surface runoff will likely increase slightly in the YARHR by the 2050s. In the long-term simulated predictions of runoff in the TRHR, precipitation is the main factor affecting the runoff, but the influence on hydrological regimes caused by continual temperature increase is also very important. The obvious vulnerability of the runoff to climate change will drive intensive efforts to understand the water cycle in permafrost regions on the Qinghai-Tibet Plateau.

Although the results presented here are promising and these data driven models can be successfully applied to establish river flow with three input parameters ANN forecasting models, these models underestimate extreme flood flow. In the future, further research is necessary to improve the prediction accuracy, especially for the flood flow, by combining or improving model parameters. For the study area of this article, we can consider trying to add the glacier melting runoff as input parameters in the ANN prediction models to improve the precision in future.

\section{Conflicts of Interest}

All authors declared that there are no conflicts of interest regarding the publication of this paper.

\section{Acknowledgments}

This study was funded by the Natural Science Foundation of China (no. 91547203 and no. 41671015), the Fundamental Research Funds for the Central Universities (Grant no. LZUJBKY-2016-171), and the National Basic Research Program of China (973, no. 2013CBA01807).

\section{References}

[1] W. Genxu, L. Shengnan, H. Hongchang, and L. Yuanshou, "Water regime shifts in the active soil layer of the Qinghai-Tibet Plateau permafrost region, under different levels of vegetation," Geoderma, vol. 149, no. 3-4, pp. 280-289, 2009.

[2] A. Frampton, S. L. Painter, and G. Destouni, "Permafrost degradation and subsurface-flow changes caused by surface warming trends," Hydrogeology Journal, vol. 21, no. 1, pp. 271280, 2013.

[3] V. F. Bense, G. Ferguson, and H. Kooi, "Evolution of shallow groundwater flow systems in areas of degrading permafrost," Geophysical Research Letters, vol. 36, no. 22, Article ID L22401, 2009.

[4] M. K. Woo, Permafrost Hydrology, Springer, Berlin, Heidelberg, Germany, 2012.

[5] D. Magritsky, V. Mikhailov, V. Korotaev, and D. Babich, "Changes in hydrological regime and morphology of river deltas in the Russian Arctic," Deltas: Landfoms, Ecosystems and Human Activities, vol. 358, pp. 67-79, 2013.

[6] A. I. Shiklomanov, R. B. Lammers, M. A. Rawlins, L. C. Smith, and T. M. Pavelsky, "Temporal and spatial variations in maximum river discharge from a new Russian data set," Journal of Geophysical Research: Biogeosciences, vol. 112, no. 4, Article ID G04S53, 2007.

[7] A. I. Shiklomanov, R. B. Lammers, D. P. Lettenmaier et al., "Hydrological changes: historical analysis, contemporary status, and future projections," in Regional Environmental Changes in Siberia and Their Global Consequences, Springer Environmental Science and Engineering, pp. 111-154, Springer, Dordrecht, Netherlands, 2013

[8] G. X. Wang, Y. S. Li, Y. B. Wang, and Y. P. Shen, "Impacts of alpine ecosystem and climate changes on surface runoff in the source region of Yangtze River," Journal of Glaciology and Geocryology, vol. 29, no. 2, pp. 159-168, 2007.

[9] L. Xiong, K. Yu, H. Zhang, and L. Zhang, "Annual runoff change in the headstream of Yangtze River and its relation to precipitation and air temperature," Hydrology Research, vol. 44, no. 5, pp. 850-874, 2013.

[10] D. Riseborough, N. Shiklomanov, B. Etzelmüller, S. Gruber, and S. Marchenko, "Recent advances in permafrost modelling," Permafrost and Periglacial Processes, vol. 19, no. 2, pp. 137-156, 2008.

[11] T. M. Carpenter and K. P. Georgakakos, "Intercomparison of lumped versus distributed hydrologic model ensemble simulations on operational forecast scales," Journal of Hydrology, vol. 329, no. 1-2, pp. 174-185, 2006.

[12] H. Xie and Y. Lian, "Uncertainty-based evaluation and comparison of SWAT and HSPF applications to the Illinois River Basin," Journal of Hydrology, vol. 481, pp. 119-131, 2013.

[13] J. W. Pomeroy, D. M. Gray, T. Brown et al., "The cold regions hydrological model: A platform for basing process representation and model structure on physical evidence," Hydrological Processes, vol. 21, no. 19, pp. 2650-2667, 2007. 
[14] Y. W. Zhou, D. X. Guo, and G. Q. Qiu, Geocryology in China, vol. 33, Science Press, Beijing, China, 2002.

[15] W. L. Quinton and P. Marsh, "A conceptual framework for runoff generation in a permafrost environment," Hydrological Processes, vol. 13, no. 16, pp. 2563-2581, 1999.

[16] G. D. Cheng and H. J. Jin, "Groundwater in the permafrost regions on the Qinghai-Tibet Plateau and its changes," Hydrogeology \& Engineering Geology, vol. 40, no. 1, pp. 1-11, 2013.

[17] J. M. McKenzie, C. I. Voss, and D. I. Siegel, "Groundwater flow with energy transport and water-ice phase change: Numerical simulations, benchmarks, and application to freezing in peat bogs," Advances in Water Resources, vol. 30, no. 4, pp. 966-983, 2007.

[18] Z. M. Yaseen, A. El-shafie, O. Jaafar, H. A. Afan, and K. N. Sayl, "Artificial intelligence based models for stream-flow forecasting: 2000-2015," Journal of Hydrology, vol. 530, pp. 829$844,2015$.

[19] S. Haykin, Neural Networks: A Comprehensive Foundation, Macmillan College Publishing Company, New York, NY, USA, 1994.

[20] V. N. Vapnik, The Nature of Statistical Learning Theory, Springer, 1995.

[21] L. A. Zadeh, "Fuzzy sets," http://dx.doi.org/10.1109/2.53, 1965.

[22] H. P. Schwefel, Numerical Optimization of Computer Models, John Wiley Sons, New York, NY, USA, 1981.

[23] A. Grossmann and J. Morlet, "Decomposition of Hardy functions into square integrable wavelets of constant shape," SIAM Journal on Mathematical Analysis, vol. 15, no. 4, pp. 723-736, 1984.

[24] O. Kisi, "The potential of different ANN techniques in evapotranspiration modelling," Hydrological Processes, vol. 22, no. 14, pp. 2449-2460, 2008.

[25] Y. Zhao, L. Guo, J. Liang, and M. Zhang, "Seasonal artificial neural network model for water quality prediction via a clustering analysis method in a wastewater treatment plant of China," Desalination and Water Treatment, vol. 57, no. 8, pp. 3452-3465, 2016.

[26] R. Joshi, K. Kumar, and V. P. S. Adhikari, "Modelling suspended sediment concentration using artificial neural networks for Gangotri glacier," Hydrological Processes, vol. 30, no. 9, pp. 13541366, 2016.

[27] A. Dahamsheh and H. Aksoy, "Markov Chain-Incorporated Artificial Neural Network Models for Forecasting Monthly Precipitation in Arid Regions," Arabian Journal for Science and Engineering, vol. 39, no. 4, pp. 2513-2524, 2014.

[28] Ö. Kişi, "Streamflow forecasting using different artificial neural network algorithms," Journal of Hydrologic Engineering, vol. 12, no. 5, pp. 532-539, 2007.

[29] R. S. Govindaraju, "Artificial neural networks in hydrology. I: preliminary concepts," Journal of Hydrologic Engineering, vol. 5, no. 2, pp. 115-123, 2000.

[30] L. A. Garcia and A. Shigidi, "Using neural networks for parameter estimation in ground water," Journal of Hydrology, vol. 318, no. 1-4, pp. 215-231, 2006.

[31] H. Yoon, S. Jun, Y. Hyun, G. Bae, and K. Lee, "A comparative study of artificial neural networks and support vector machines for predicting groundwater levels in a coastal aquifer," Journal of Hydrology, vol. 396, no. 1-2, pp. 128-138, 2011.

[32] J. Chang, G. Wang, and T. Mao, "Simulation and prediction of suprapermafrost groundwater level variation in response to climate change using a neural network model," Journal of Hydrology, vol. 529, pp. 1211-1220, 2015.
[33] G. K. C. Clarke, E. Berthier, C. G. Schoof, and A. H. Jarosch, "Neural networks applied to estimating subglacial topography and glacier volume," Journal of Climate, vol. 22, no. 8, pp. 21462160, 2009.

[34] V. M. Moya Quiroga, A. Mano, Y. Asaoka, S. Kure, K. Udo, and J. Mendoza, "Snow glacier melt estimation in tropical Andean glaciers using artificial neural networks," Hydrology and Earth System Sciences, vol. 17, no. 4, pp. 1265-1280, 2013.

[35] S. Haykin, Neural Networks: A Comprehensive Foundation, Prentice-Hall, Englewood Cliffs, New Jersey, USA, 2nd edition, 1999.

[36] J. Xu, Y. Chen, W. Li, Q. Nie, C. Song, and C. Wei, "Integrating wavelet analysis and BPANN to simulate the annual runoff with regional climate change: a case study of Yarkand River, Northwest China," Water Resources Management, vol. 28, no. 9, pp. 2523-2537, 2014.

[37] M. T. Sattari, H. Apaydin, and F. Ozturk, "Flow estimations for the Sohu Stream using artificial neural networks," Environmental Earth Sciences, vol. 66, no. 7, pp. 2031-2045, 2012.

[38] A. G. Yilmaz, M. A. Imteaz, and G. Jenkins, "Catchment flow estimation using Artificial Neural Networks in the mountainous Euphrates Basin," Journal of Hydrology, vol. 410, no. 1-2, pp. 134-140, 2011.

[39] S. Abudu, J. P. King, and A. S. Bawazir, "Forecasting monthly streamflow of spring-summer runoff season in Rio Grande headwaters basin using stochastic hybrid modeling approach," Journal of Hydrologic Engineering, vol. 16, no. 4, pp. 384-390, 2011.

[40] K. Chokmani, T. B. M. J. Ouarda, S. Hamilton, M. H. Ghedira, and H. Gingras, "Comparison of ice-affected streamflow estimates computed using artificial neural networks and multiple regression techniques," Journal of Hydrology, vol. 349, no. 3-4, pp. 383-396, 2008.

[41] P. Nilsson, C. B. Uvo, and R. Berndtsson, "Monthly runoff simulation: Comparing and combining conceptual and neural network models," Journal of Hydrology, vol. 321, no. 1-4, pp. 344363, 2006.

[42] J. Chang, G. Wang, C. Li, and T. Mao, "Seasonal dynamics of suprapermafrost groundwater and its response to the freeingthawing processes of soil in the permafrost region of QinghaiTibet Plateau," Science China Earth Sciences, vol. 58, no. 5, pp. 727-738, 2015.

[43] X. Liu, J. Zhang, X. Zhu et al., "Spatiotemporal changes in vegetation coverage and its driving factors in the Three-River Headwaters Region during 2000-2011," Journal of Geographical Sciences, vol. 24, no. 2, pp. 288-302, 2014.

[44] G. Cheng and T. Wu, "Responses of permafrost to climate change and their environmental significance, Qinghai-Tibet Plateau," Journal of Geophysical Research, vol. 112, no. 2, Article ID F02S03, 2007.

[45] J. Yang, Y. Ding, and R. Chen, "Climatic causes of ecological and environmental variations in the source regions of the Yangtze and Yellow Rivers of China," Environmental Geology, vol. 53, no. 1, pp. 113-121, 2007.

[46] G. Wang, W. Bai, N. Li, and H. Hu, "Climate changes and its impact on tundra ecosystem in Qinghai-Tibet Plateau, China," Climatic Change, vol. 106, no. 3, pp. 463-482, 2011.

[47] S. Zhang, D. Hua, X. Meng, and Y. Zhang, "Climate change and its driving effect on the runoff in the 'Three-River Headwaters' region," Journal of Geographical Sciences, vol. 21, no. 6, pp. 963978, 2011. 
[48] Y. Lan, G. Zhao, Y. Zhang, J. Wen, J. Liu, and X. Hu, "Response of runoff in the source region of the Yellow River to climate warming," Quaternary International, vol. 226, no. 1-2, pp. 6065, 2010.

[49] L. Li, H. Shen, S. Dai, H. Li, and J. Xiao, "Response of water resources to climate change and its future trend in the source region of the Yangtze River," Journal of Geographical Sciences, vol. 23, no. 2, pp. 208-218, 2013.

[50] T. Mao, G. Wang, and T. Zhang, "Impacts of Climatic Change on Hydrological Regime in the Three-River Headwaters Region, China, 1960-2009," Water Resources Management, vol. 30, no. 1, pp. 115-131, 2016.

[51] K. Qian, X.-S. Wang, J. Lv, and L. Wan, “The wavelet correlative analysis of climatic impacts on runoff in the source region of Yangtze River, in China," International Journal of Climatology, vol. 34, no. 6, pp. 2019-2032, 2014.

[52] X. S. Yi, G. S. Li, and Y. Y. Yin, "Temperature variation and abrupt change analysis in the Three-River Headwaters Region during 1961-2010," Journal of Geographical Sciences, vol. 22, no. 3, pp. 451-469, 2012.

[53] K. P. Sudheer, A. K. Gosain, and K. S. Ramasastri, "A data-driven algorithm for constructing artificial neural network rainfallrunoff models," Hydrological Processes, vol. 16, no. 6, pp. 13251330, 2002.

[54] J. Lin, C. Cheng, and K. Chau, "Using support vector machines for long-term discharge prediction," Hydrological Sciences Journal, vol. 51, no. 4, pp. 599-612, 2006.

[55] C. Shu and T. B. M. J. Ouarda, "Regional flood frequency analysis at ungauged sites using the adaptive neuro-fuzzy inference system," Journal of Hydrology, vol. 349, no. 1-2, pp. 3143, 2008.

[56] Y. F. Shi, Concise glacier inventory of China, Shanghai Popular Science Press, Shanghai, China, 2008.

[57] L. Qiao, L. Shiyin, G. Wanqin et al., "Glacier changes in the Lancang River Basin, China, between 1968-1975 and 2005-2010," Arctic, Antarctic, and Alpine Research, vol. 47, no. 2, pp. 335-344, 2015.

[58] Z. X. Xu, F. F. Zhao, and J. Y. Li, "Response of streamflow to climate change in the headwater catchment of the Yellow River basin," Quaternary International, vol. 208, no. 1-2, pp. 62-75, 2009.

[59] Z. Yao, Z. Liu, H. Huang, G. Liu, and S. Wu, "Statistical estimation of the impacts of glaciers and climate change on river runoff in the headwaters of the Yangtze River," Quaternary International, vol. 336, pp. 89-97, 2014.

[60] B. Ye, D. Yang, Z. Zhang, and D. L. Kane, "Variation of hydrological regime with permafrost coverage over Lena Basin in Siberia," Journal of Geophysical Research Atmospheres, vol. 114, no. 7, Article ID D07102, 2009.

[61] L. C. Smith, T. M. Pavelsky, G. M. MacDonald, A. I. Shiklomanov, and R. B. Lammers, "Rising minimum daily flows in northern Eurasian rivers: A growing influence of groundwater in the high-latitude hydrologic cycle," Journal of Geophysical Research: Biogeosciences, vol. 112, no. 4, Article ID G04S47, 2007.

[62] S. Ge, J. McKenzie, C. Voss, and Q. Wu, "Exchange of groundwater and surface-water mediated by permafrost response to seasonal and long term air temperature variation," Geophysical Research Letters, vol. 38, no. 14, Article ID L14402, 2011. 

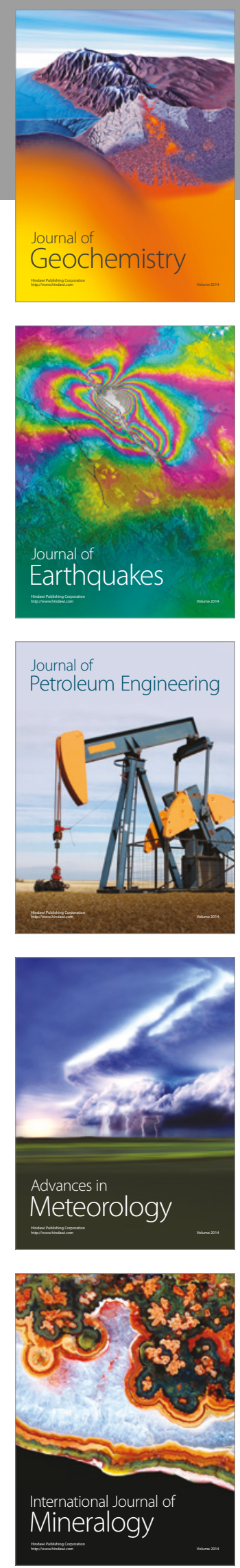
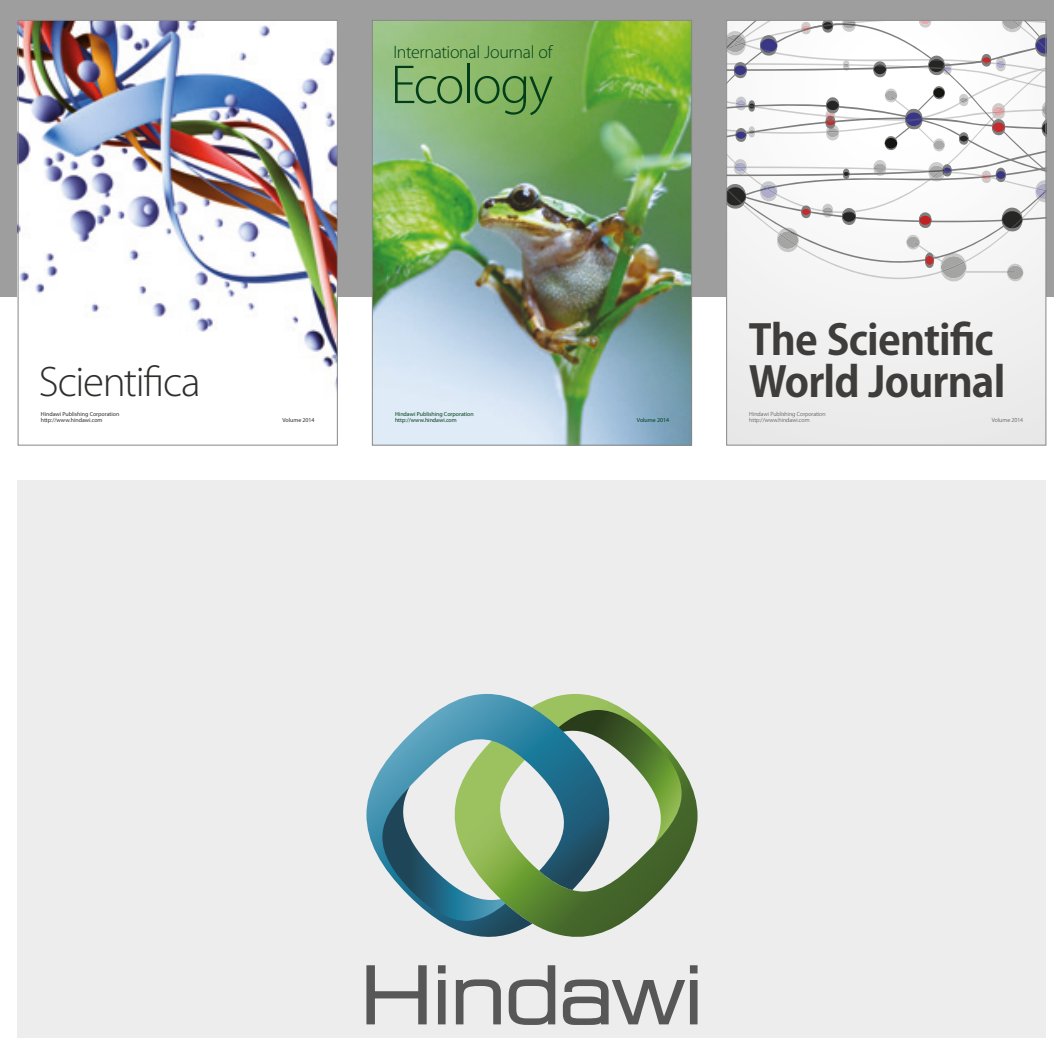

Submit your manuscripts at

https://www.hindawi.com
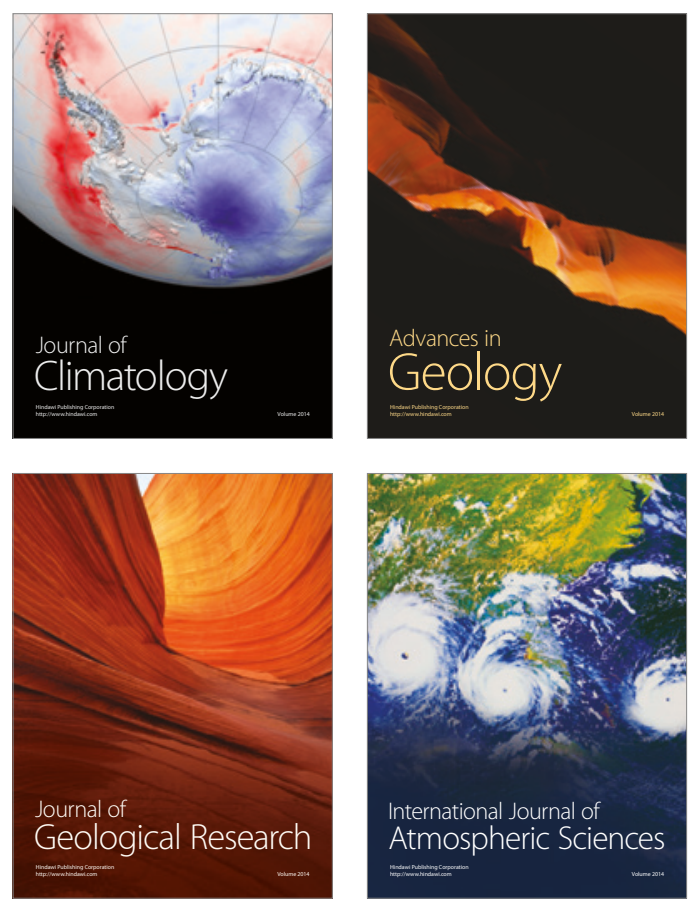

The Scientific

World Journal
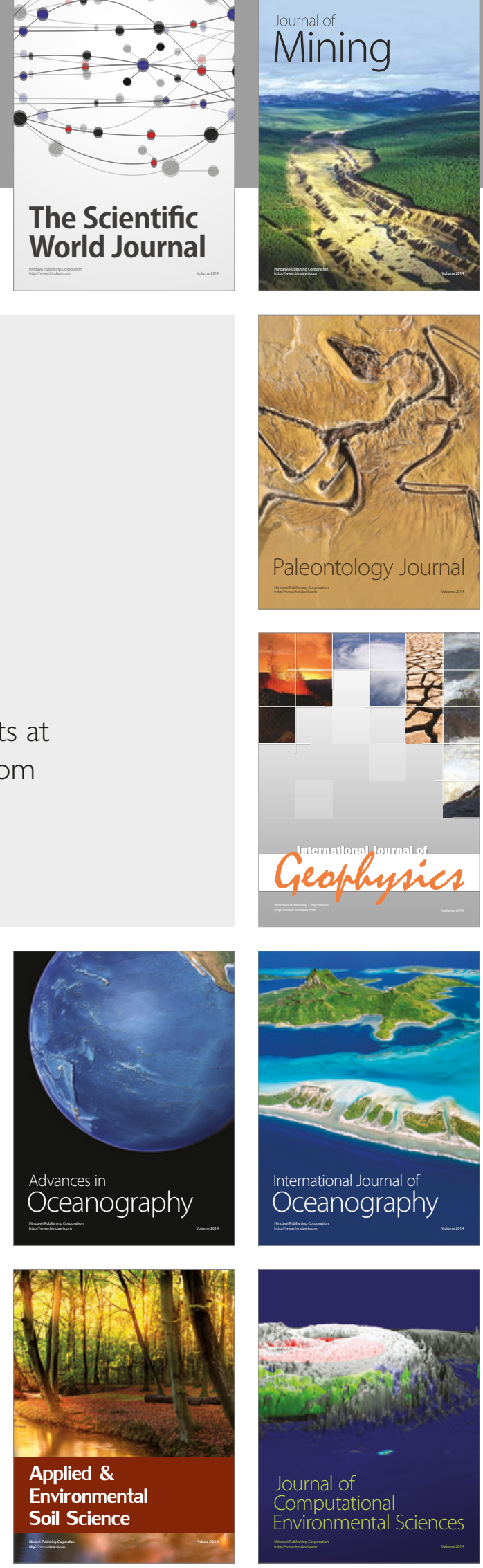